\title{
Characterisation of a stratospheric sulfate plume from the Nabro volcano using a combination of passive satellite measurements in nadir and limb geometry
}

\author{
M. J. M. Penning de Vries ${ }^{1}$, S. Dörner ${ }^{1}$, J. Puķīte ${ }^{1}$, C. Hörmann ${ }^{1}$, M. D. Fromm ${ }^{2}$, and T. Wagner ${ }^{1}$ \\ ${ }^{1}$ Max Planck Institute for Chemistry, Hahn-Meitner-Weg 1, 55128 Mainz, Germany \\ ${ }^{2}$ U.S. Naval Research Laboratory, 4555 Overlook Ave, SW Washington, DC 20375, USA
}

Correspondence to: M. J. M. Penning de Vries (marloes.penningdevries@ mpic.de)

Received: 6 February 2014 - Published in Atmos. Chem. Phys. Discuss.: 21 March 2014

Revised: 3 July 2014 - Accepted: 4 July 2014 - Published: 14 August 2014

\begin{abstract}
The eruption of the Nabro volcano (Eritrea), which started on 12 June 2011, caused the introduction of large quantities of $\mathrm{SO}_{2}$ into the lower stratosphere. The subsequently formed sulfate aerosols could be detected for several months following the eruption. It is generally assumed that the formation of sulfate aerosols in the stratosphere is a relatively slow process, but in plumes from explosive eruptions significant amounts of aerosols have been seen to form within a few hours.

We show that sulfate aerosols were present in the lower stratosphere within hours of the onset of the eruption of Nabro. Evidence comes from nadir UV Aerosol Index (UVAI) and $\mathrm{SO}_{2}$ measurements by SCIAMACHY, GOME-2 and OMI, and limb aerosol measurements by SCIAMACHY. The sulfate plume displays negative UVAI in the western part of OMI's swath and positive UVAI in the eastern part - an effect that is due to the strong viewing angle dependence of UVAI and can only be caused by a high-altitude $(>11 \mathrm{~km})$, non-absorbing (single-scattering albedo >0.97) aerosol plume. For the retrieval of the aerosol profile from limb measurements, the horizontal dimensions and the position of the aerosol plume need to be taken into account, otherwise both extinction and layer height may be underestimated appreciably. By combining nadir $\mathrm{SO}_{2}$ column density and UVAI with limb aerosol profiles, a stratospheric plume from Nabro could be tracked from 13 to 17 June, before the plumes from later, lower-altitude explosions started interfering with the signal. Our findings are in agreement with ground-based lidar and sun-photometer data from an
\end{abstract}

MPLNET/AERONET station in Israel and with data from the satellite-borne CALIOP lidar.

\section{Introduction}

Volcanic eruptions are an important source of sulfate aerosols to the stratosphere due to the emission of large quantities of the precursor $\mathrm{SO}_{2}$. In the stratosphere, low gas-phase oxidation rates of $\mathrm{SO}_{2}$ cause a relatively slow build-up of sulfate aerosols and low deposition rates cause aerosol lifetimes on the order of months to years (e.g. Bluth et al. (1997) and references therein). The presence of sulfate aerosols in the stratosphere has wide-ranging effects: their purely scattering (non-absorbing) nature in the UV-visible wavelength range causes radiative cooling at the Earth's surface as the aerosol layer reflects more solar radiation into space. Local warming of the stratosphere due to absorption of upwelling long-wave surface radiation by sulfate droplets has also been shown to occur. In addition, the increased total aerosol (reactive) surface area leads to enhanced ozone destruction (see e.g. Hofmann and Solomon (1989); Hansen et al. (1992); McCormick et al. (1995); Bluth et al. (1997); Robock (2000); SPARC (2006); Solomon et al. (2011) and references therein for all above-mentioned effects). The climatic effects of large volcanic eruptions can be substantial, which was recently seen in the comparatively cold year that followed the eruption of Mount Pinatubo in 1991 (McCormick et al., 1995; Kirchner et al., 1999; Robock, 2000; Soden et al., 2002). 
The eruption of the Nabro volcano in Eritrea (at $13.37^{\circ} \mathrm{N}$, $41.7^{\circ} \mathrm{E}$ ) that started on 12 June 2011 , and lasted for several weeks was exceptional with regard to the large amount of $\mathrm{SO}_{2}$ emitted (Theys et al., 2013); the resulting sulfate aerosol plume could be tracked for months while it encircled the Northern Hemisphere both from the west and the east (Bourassa et al., 2012). A large fraction of the volcanic plumes was injected below the local tropopause (dynamic tropopause at $16.8 \mathrm{~km}$ altitude according to ECMWF), but this was not the case for the plume from the first explosion (and possibly later plumes) from Nabro. In contrast to the analysis in Bourassa et al. (2012), evidence has emerged that at least parts of the initial volcanic plume (emitted on 1213 June, and here referred to as the first volcanic plume) were emitted at the top of or even above the tropopause and were located above $10 \mathrm{~km}$, with a maximum around 18$19 \mathrm{~km}$ within hours of the eruption (Sawamura et al., 2012; Fromm et al., 2013; Vernier et al., 2013; Fairlie et al., 2014; Clarisse et al., 2014).

One of the main removal mechanisms of $\mathrm{SO}_{2}$ in the atmosphere is the oxidation to $\mathrm{H}_{2} \mathrm{SO}_{4}$ and the subsequent formation of (or uptake in) aerosol particles. For stratospheric eruptions, the conversion time of $\mathrm{SO}_{2}$ to sulfate aerosols was empirically found to be on the order of 30-40 days (e-folding time of $\mathrm{SO}_{2}$ loss (see Bluth et al. (1997) and references therein). This assumption is based on data from eruption plumes at altitudes above $25 \mathrm{~km}$ (Pinatubo and $\mathrm{El}$ Chichón) and $\mathrm{SO}_{2}$ life times are much shorter for volcanic plumes at lower altitudes or with higher water vapour content: life times of the order of 1-2 weeks were found for Kasatochi (Krotkov et al., 2010), Sarychev (Haywood et al., 2010), and Cerro Hudson (Constantine et al., 2000). For the earliest emitted "high-altitude" plumes (at 15-18 km) from Nabro, an $\mathrm{SO}_{2}$ life time of 5 days was found (Theys et al., 2013) and, consequently, an amount of sulfate aerosols large enough to be visible from space could be observed within at most $36 \mathrm{~h}$ of the eruption. This is in agreement with a study by Sawamura et al. (2012), who report the presence of an aerosol plume in the lower stratosphere at $17 \mathrm{~km}$ altitude using data from a ground-based lidar station in Sede Boker, Israel, approximately $30 \mathrm{~h}$ downwind of the first explosion of Nabro.

For the investigation of the first plume from the Nabro eruption we use the satellite-borne spectrometers SCIAMACHY (SCanning Imaging Absorption spectroMeter for Atmospheric CHartographY), GOME-2 (Global Ozone Monitoring Experiment), and OMI (Ozone Monitoring Instrument). The primary goal of these instruments is the measurement of various trace gases in the atmosphere, which is why spatial resolution is sacrificed in favour of higher spectral resolution - a dedicated aerosol instrument like MODIS (MODerate resolution Imaging Spectroradiometer) has a $300 \times($ for OMI) to $3000 \times($ GOME-2) higher spatial resolution. With these large ground pixels, cloud contamination is a serious issue for aerosol retrieval from such spectrometers (Krijger et al., 2007). To avoid this problem, we make use of UV Aerosol Indices (UVAI), which can be determined in the presence of clouds (Torres et al., 1998; de Graaf et al., 2005; Penning de Vries and Wagner, 2011). Despite the fact that the quantitative application of UVAI is not straightforward, it can be used to distinguish between UV-absorbing aerosols and aerosols that do not or barely absorb UV radiation (Penning de Vries et al., 2009), especially for high-altitude aerosol plumes. This makes the UVAI a tool particularly suited for the study of volcanic plumes, which may contain either (absorbing) ash or (non-absorbing) sulfate aerosols, or both. It has been shown in the past that UVAI depend on solar and viewing geometry (de Graaf et al., 2005), but we show that the effect can be particularly dramatic for high-altitude plumes, and is even capable of changing the sign of UVAI caused by purely scattering aerosol layers from negative to positive.

Once aerosols reach the upper troposphere or lower stratosphere, e.g. in the course of a volcanic eruption, their profile can be studied using space-based measurements in limb geometry. The SCIAMACHY instrument (2002-2012) made consecutive scans in limb and nadir geometry, allowing the study of trace gas profiles together with their co-located total column amount (Bovensmann et al., 1999). First successful attempts at aerosol retrieval from SCIAMACHY limb measurements have only recently been published (Ovigneur et al., 2011; Taha et al., 2011; Ernst et al., 2012). We present results from a new limb aerosol retrieval approach and demonstrate the limitations of conventional limb retrievals when faced with plumes with a limited horizontal extent such as those emitted by volcanoes and wildfires.

\section{Methods and data}

\subsection{Instrumentation}

The SCIAMACHY instrument was launched on ENVISAT in March, 2002, into a daytime-descending polar orbit located at approximately $800 \mathrm{~km}$ from the Earth's surface (Bovensmann et al., 1999; Wagner et al., 2008; Gottwald and Bovensmann, 2011). SCIAMACHY's swath is $960 \mathrm{~km}$ wide, and global coverage is achieved approximately every 6 days. The instrument measures backscattered radiance in the UVNIR range $(240-2380 \mathrm{~nm})$. One feature that makes SCIAMACHY unique is the alternating measurements in the limb and nadir modes, which allow co-located measurements of the total column of atmospheric constituents (in nadir geometry) and their stratospheric profile (in limb geometry). The alternation of measurements in limb and nadir geometry is the reason for the division of the orbit into subsets of measurements called states. Whereas nadir ground pixels generally measure $30 \times 60 \mathrm{~km}^{2}$, limb pixels are approximately $240 \mathrm{~km}$ wide and have a vertical resolution of about $3 \mathrm{~km}$ (Bovensmann et al., 1999; Gottwald and Bovensmann, 2011). Since 
April 2012, all communications with ENVISAT have been lost, which put an end to several successful and long-lasting missions on the platform - SCIAMACHY among them.

GOME-2 on METOP-A is very similar to SCIAMACHY, although it measures in a smaller spectral range (240$790 \mathrm{~nm}$ ) and lacks the possibility of limb measurements (Callies et al., 2000). The spatial resolution is comparable $\left(40 \times 80 \mathrm{~km}^{2}\right)$, but because GOME-2's swath is twice as wide as SCIAMACHY's, and due to the fact that it measures in nadir geometry only, GOME-2 achieves global coverage in 1.5 days. Once per month, the instrument operates in the narrow-swath mode, reducing the pixel width (and swath width) by a factor of 8 , approximately $40 \times 10 \mathrm{~km}^{2}$ : the same resolution as the polarisation measurement devices (PMDs). The main function of the PMDs is to provide input for the polarisation correction of measured radiances, but they can also be used for the detection of clouds (Grzegorski et al., 2006) or the determination of UVAI (de Graaf et al., 2013).

The OMI on the AURA satellite has a much higher spatial resolution: at the centre of the swath, the pixels measure $13 \times 24 \mathrm{~km}^{2}$. OMI has been performing measurements in the UV-visible wavelength range from its daytime ascending polar orbit since 2004 (Levelt et al., 2006). Its wide swath of $2600 \mathrm{~km}$ allowed daily global coverage until the first occurrence of the so-called row anomaly in June 2007, an instrumental problem that causes grievous radiance errors in up to half of OMI's ground pixels (van Hoek and Claas, 2010). Currently, neither $\mathrm{SO}_{2}$ columns (from our retrieval), nor UVAI can be reliably determined from pixels affected by the row anomaly which we therefore removed from the data set prior to analysis (although different criteria were used to filter $\mathrm{SO}_{2}$ and UVAI data sets). In the future, many more OMI pixels might be eligible for $\mathrm{SO}_{2}$ retrieval - see e.g. the study by Yan et al. (2012).

\subsection{UV Aerosol Indices}

To investigate whether ash was present in the volcanic plume we use the UVAI (also known as "residue"). The definition of the UVAI is based on the principle that aerosol optical properties differ from those of molecules, so that the presence of an aerosol layer leads to a change in contrast between the reflectance at a wavelength $\lambda($ e.g. $340 \mathrm{~nm})$ and at a reference wavelength $\lambda_{0}$ (e.g. $380 \mathrm{~nm}$ ) in comparison to an aerosol-free atmosphere. The calculation of UVAI requires radiative transfer modelling of reflectances at $\lambda$ and $\lambda_{0}$ for aerosol-free scenes bounded by a Lambertian surface with an albedo value chosen such that measured and modelled reflectances at $\lambda_{0}$ are equal. The UVAI is obtained by calculating the ratio between the measured $\left(R^{\text {meas }}\right)$ and modelled $\left(R^{\text {model }}\right)$ reflectances at $\lambda$ (Torres et al., 1998):

$\mathrm{UVAI}=-100 \cdot \log _{10}\left(\frac{R^{\text {meas }}}{R^{\text {model }}}\right)_{\lambda}$.
Positive values of UVAI are commonly referred to as AAI (Absorbing Aerosol Index), which is a well-known and much-used qualitative indicator of aerosols that absorb radiation in the UV range, such as mineral dust, biomass burning smoke and volcanic ash (Herman et al., 1997; Torres et al., 1998; de Graaf et al., 2005). The AAI depends on plume altitude and is most sensitive to elevated layers of absorbing aerosols, in particular if these are located over bright surfaces such as ice or clouds (see e.g. Hsu et al., 1999; Fromm et al., 2010). The SCI (SCattering Index), which consists of UVAI $<0$, was only recently introduced as an indicator for aerosols that do not or only weakly absorb UV radiation (Penning de Vries et al., 2009), such as sulfate aerosols and other secondary aerosols formed from anthropogenic or biogenic emissions of trace gases. UVAI generally depends on aerosol amount, size distribution, absorption and altitude. The AAI is more sensitive to aerosol amount and plume altitude than the SCI because absorption by aerosols causes larger changes in spectral contrast in the UV range than aerosol scattering (Torres et al., 1998; de Graaf et al., 2005; Penning de Vries et al., 2009). A big advantage of the UVAI is that it can be meaningfully interpreted in the presence of clouds; however, clouds influence UVAI and must be taken into account for quantitative analysis of UVAI (Penning de Vries and Wagner, 2011).

There are several different definitions of UVAI in existence; here we use KNMI's AAI product for SCIAMACHY, which is determined using 340 and $380 \mathrm{~nm}$ radiances (available at http://www.temis.nl/). For consistency, OMI "OMAERUV" UVAI data obtained from the same wavelengths were used (downloaded from http://mirador. gsfc.nasa.gov/). GOME-2 UVAI are available from radiances measured using two of the instrument's PMD channels centred at 338 and $382 \mathrm{~nm}$ (de Graaf et al., 2013). Not only do the PMD UVAI have the advantage of an approximately $8 \times$ higher spatial resolution, the UVAI also appears less noisy than the science channel product, which probably has to do with the better co-location of the radiance measurements at the two wavelengths required for the UVAI calculation. The correlation between UVAI determined from GOME-2's science channels on the one hand, and the PMD UVAI on the other is excellent, although we found that an offset of 0.5 units had to be subtracted - possibly to account for differences in polarisation sensitivity and calibration.

\subsection{Limb extinction profiles}

For the determination of the extinction profile of the volcanic aerosol plume we applied a newly developed retrieval algorithm to SCIAMACHY limb intensity data measured at $750 \mathrm{~nm}$. Because the intensity at a certain tangent height (TH) is not only influenced by particles at that particular altitude, but also by particles in the layers above, an onion peeling method is applied. That means that the retrieval is applied to the intensity measured at each $\mathrm{TH}$ in sequence, starting at 
the top $(\mathrm{TH}=31.5 \mathrm{~km})$, taking into account the retrieval results from the higher layers. The intensity at $\mathrm{TH}=34.5 \mathrm{~km}$ is used to normalise the data. For the presented study of a volcanic plume, the onion peeling method is iterated at least twice to ensure the effects of particles in lower layers (which influence the intensity at the THs above if the layer is optically dense) are properly accounted for. The retrieval consists of online radiative transfer calculations at every TH. In each calculation step the extinction is varied iteratively until the simulated intensity matches the measurement. The simulations are performed using the full spherical 3-D Monte Carlo model McArtim (Deutschmann et al., 2011) with an effective surface albedo from the matching nadir measurements and aerosol parameters representative of sulfate particles (singlescattering albedo 1.0 , asymmetry parameter $g=0.6$, corresponding to a size distribution with a mean diameter of $80 \mathrm{~nm}$ and width $=1.6$, Deshler, 2008) as input. The SCIAMACHY limb retrieval method will be described in more detail in a forthcoming publication.

The findings from the extinction retrieval are supported by results from the Colour Index method. Colour indices (CIs) have been used in the past to estimate particle abundance in the stratosphere (Sarkissian et al., 1991; Enell et al., 1999; von Savigny et al., 2005). The ratio of the intensity $(I)$ at two wavelengths (e.g. $\lambda_{1}=750 \mathrm{~nm}$ and $\lambda_{2}=1090 \mathrm{~nm}$ ) at a certain tangent height $\theta$ is a measure of the particle loading of the atmosphere which is based on the difference between the effect of weakly wavelength-dependent scattering on particles and that of strongly wavelength-dependent molecular scattering. The CI $R_{\mathrm{c}}$ is thus defined as

$R_{\mathrm{c}}(\theta)=\frac{I\left(\lambda_{2}, \theta\right)}{I\left(\lambda_{1}, \theta\right)}$

Scenes containing aerosols and/or clouds show higher colour index values than those with background conditions.

\section{$2.4 \mathrm{SO}_{2}$ data}

As one of the most abundant gases in a volcanic plume, $\mathrm{SO}_{2}$ is often used as a tracer for volcanic emissions by a variety of spectroscopic remote sensing techniques. It can be very well measured using DOAS (Differential Optical Absorption Spectroscopy, see e.g. Platt and Stutz, 2008; Richter and Wagner, 2011) due to the strong characteristic absorption features in the UV spectral range, both from the ground (e.g. Galle et al., 2003; Bobrowski and Platt, 2007) and from space (e.g. Eisinger and Burrows, 1998; Khokhar et al., 2005). The DOAS method is usually only applied to weak absorbers with optical densities below 0.05 , in which case the effective light path can be assumed to be wavelength-independent within the considered range of analysis. Standard DOAS evaluation schemes take advantage of the relatively high sensitivity to $\mathrm{SO}_{2}$ within the wavelength range of $310-325 \mathrm{~nm}$, but in the course of a major volcanic eruption, the $\mathrm{SO}_{2}$ optical density can easily exceed 0.2 within that range. In such cases, the effective light path becomes dependent on wavelength. As a consequence, the $\mathrm{SO}_{2}$ vertical column density is strongly underestimated by standard fit procedures in the UV range (Yang et al., 2007; Bobrowski et al., 2010; Hörmann et al., 2013). To account for the non-linear radiative transfer effects of the DOAS retrieval during the $\mathrm{SO}_{2}$-rich eruption of Nabro, a combined, multi-wavelength fit-window approach was adopted for the retrieval of $\mathrm{SO}_{2}$ by SCIAMACHY, GOME-2, and OMI as described in Hörmann et al. (2013); satellite measurements clearly affected by strong $\mathrm{SO}_{2}$ absorptions in the standard wavelength range of 312.1$324 \mathrm{~nm}$ (i.e. surpassing a threshold $\mathrm{SO}_{2}$ slant column density of $1 \times 10^{18} \mathrm{molec}^{-2}$, or about $37 \mathrm{DU}$ ) were re-analysed using an alternative wavelength range of $326.5-335.3 \mathrm{~nm}$. The vertical column density (VCD) was calculated from the measured slant column density (SCD) by using an air mass factor (AMF) to account for the effective light path through the atmosphere (Solomon et al., 1987):

$\mathrm{VCD}=\mathrm{SCD} / \mathrm{AMF}$

As the volcanic $\mathrm{SO}_{2}$ plume was located at high altitudes, the AMF was calculated based on geometrical considerations only.

\section{The June 2011 eruption of Nabro}

The Nabro volcano had been presumed extinct before the sudden, explosive eruption that started in the late evening of 12 June 2011 (Smithsonian Institution, 2011). An ice cloud was seen to emerge from Nabro at 21:00 UTC by SEVIRI (Vernier et al., 2013) and an hour later by MODIS-AQUA (Fromm et al., 2013). Nabro's eruption, which was monitored by many different satellite instruments, was exceptional with regard to the total amount of emitted $\mathrm{SO}_{2}: 4-5 \mathrm{Tg}$ were estimated to have been released within the first 15 days (Theys et al., 2013), the most active period of the eruption. This compares to approximately $20 \mathrm{Tg} \mathrm{SO}$ from Pinatubo (Bluth et al., 1993), the largest eruption of the past 100 years. The total stratospheric aerosol optical depth, resulting from the conversion of volcanic $\mathrm{SO}_{2}$ to sulfate aerosols, was the highest measured by the space-based limb-sounding OSIRIS instrument since its launch in 2001 (Bourassa et al., 2012). Whereas at least one - the first - of the numerous explosive eruptions was observed to inject gases and particles into the stratosphere (as presented here, but also in Vernier et al., 2013; Fromm et al., 2013; Fairlie et al., 2014; Clarisse et al., 2014), most of the emissions occurred at much lower altitudes. We here focus on the first plume from the eruption of Nabro because it is clearly separated from other plumes; the continuous volcanic emission of $\mathrm{SO}_{2}$ during the following days complicates the identification of individual plumes. The first plume was initially detected by GOME- 2 and IASI at 06:25 UTC on 13 June and contained approximately $0.5 \mathrm{Tg}$ $\mathrm{SO}_{2}$ (L. Clarisse and N. Theys, personal communication, 

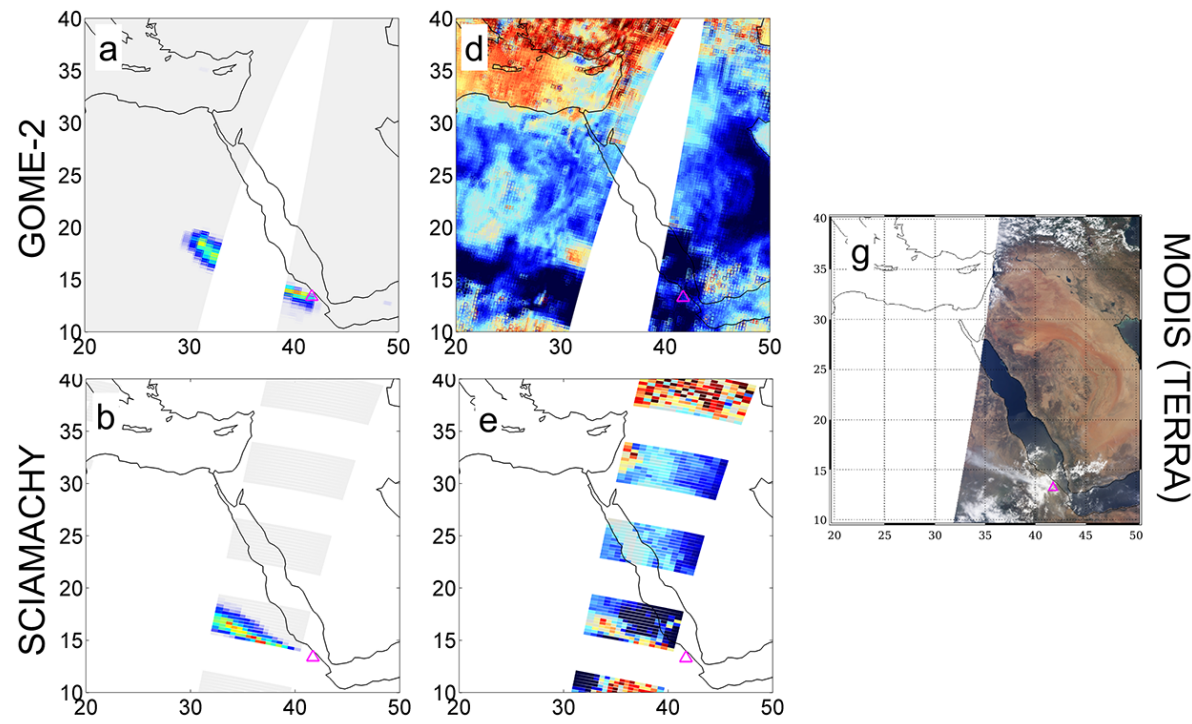

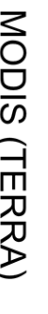
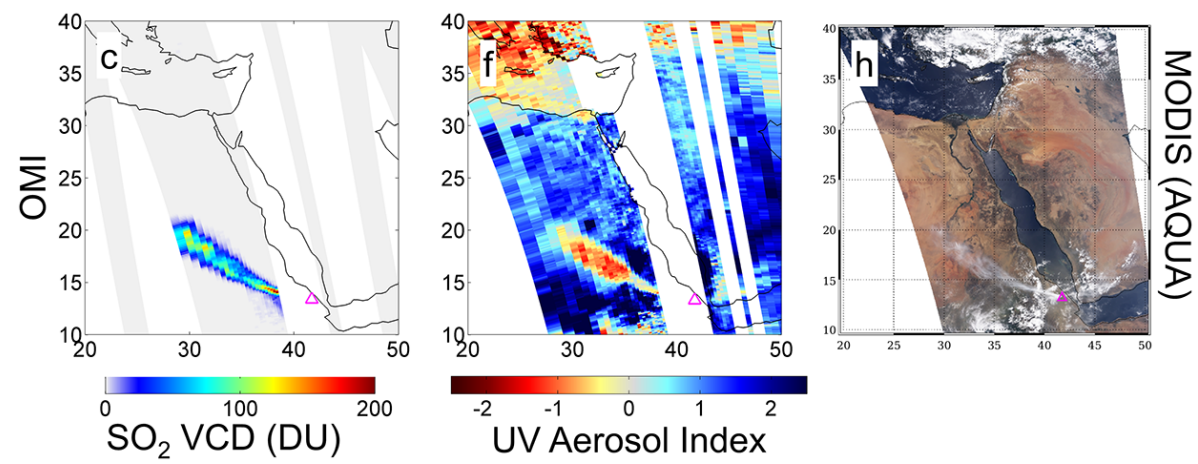

Figure 1. $\mathrm{SO}_{2}$ vertical column density in Dobson Units (panels a-c) and UV Aerosol Index (d-f) from GOME-2 (a and d), SCIAMACHY (b and $\mathbf{e}$ ) and OMI (c and $\mathbf{f}$ ) and true-colour images from MODIS on TERRA and AQUA ( $\mathbf{g}$ and $\mathbf{h}$ ) of the region around the Nabro volcano on 13 June 2011. Pink triangles indicate the location of the volcano. The overpass times (UTC) of the different instruments are: 06:25 and 08:05 for GOME-2, 07:40 for MODIS-TERRA, 07:50 for SCIAMACHY, 10:50 for MODIS-AQUA and 11:00 for OMI.

2013), thereby contributing roughly $10 \%$ to the total $\mathrm{SO}_{2}$ mass.

\section{Results}

\subsection{Nadir satellite data: $\mathrm{SO}_{2}$ columns and UV Aerosol Indices}

Figure 1 shows nadir data from four different satellite instruments (GOME-2, SCIAMACHY, OMI, and MODIS) taken on 13 June, shortly after the onset of the eruption. Assuming that Nabro started emitting $\mathrm{SO}_{2}$ at 21:00 UTC on 12 June (Vernier et al., 2013), the plume's leading edge is 11 and $14 \mathrm{~h}$ old at the time of the GOME-2 and OMI overpasses, respectively. The $\mathrm{SO}_{2}$ plume initially stretches from the volcano (pink triangle in the lower right of each figure) to the northwest and fans out slightly, as shown in Fig. 1 for GOME-2, SCIAMACHY, and OMI (panels a-c). Panels $d-f$ present the corresponding UVAI; please note that the colour scale of the UVAI was adapted to show non-absorbing aerosols (SCI, or UVAI $<0$ in yellow-red tones) in addition to UV-absorbing particles (AAI, or UVAI $>0$ in blue). As UVAI is most sensitive to UV-absorbing aerosols, panels $\mathrm{d}-\mathrm{f}$ are dominated by UVAI $>0$, indicating the presence of elevated mineral dust. It is difficult to visually confirm elevated dust over the desert, but similar patches of positive UVAI over this same domain were a common feature on several days before the eruption (not shown here, but available on www.temis.nl/airpollution/absaai). Plumes of (reddish) dust can also be seen crossing the Red Sea by close inspection of the MODIS images. In the northwest corner and over the Mediterranean Sea UVAI $<0$ can be seen that originate from broken cloud scenes (compare panels $\mathrm{g}-\mathrm{h}$ ) and presumably from non-absorbing pollution aerosols. 

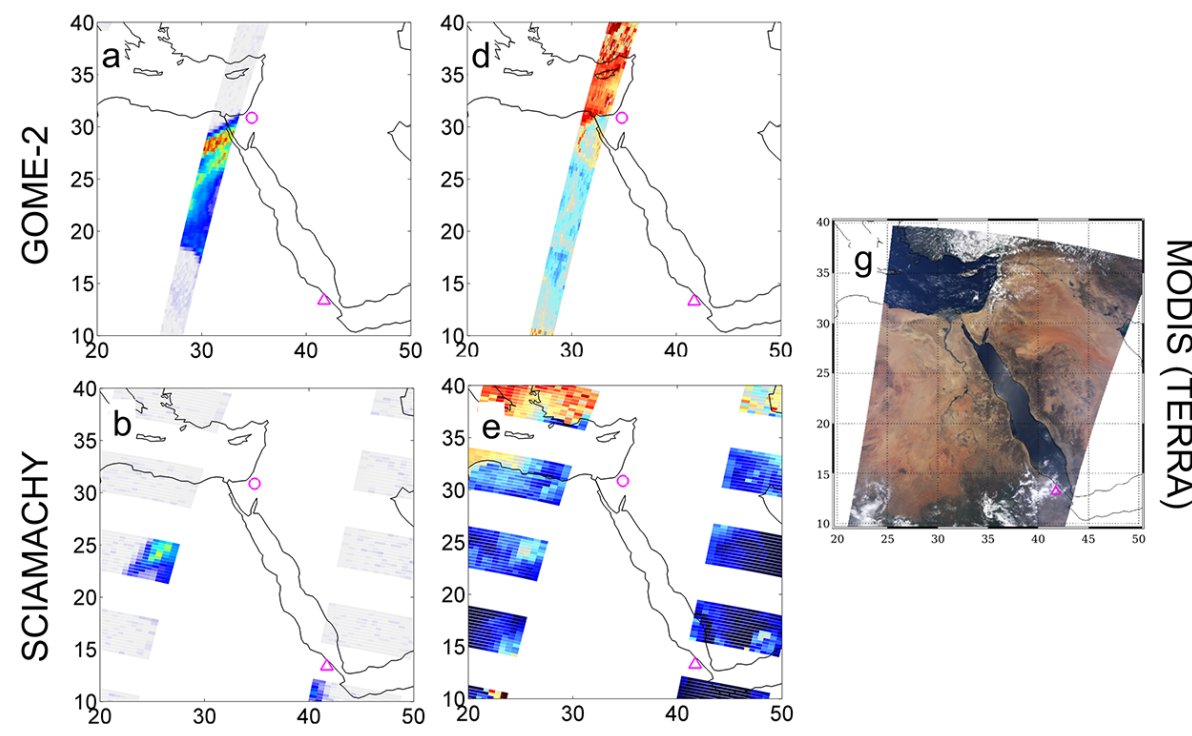

\section{商}
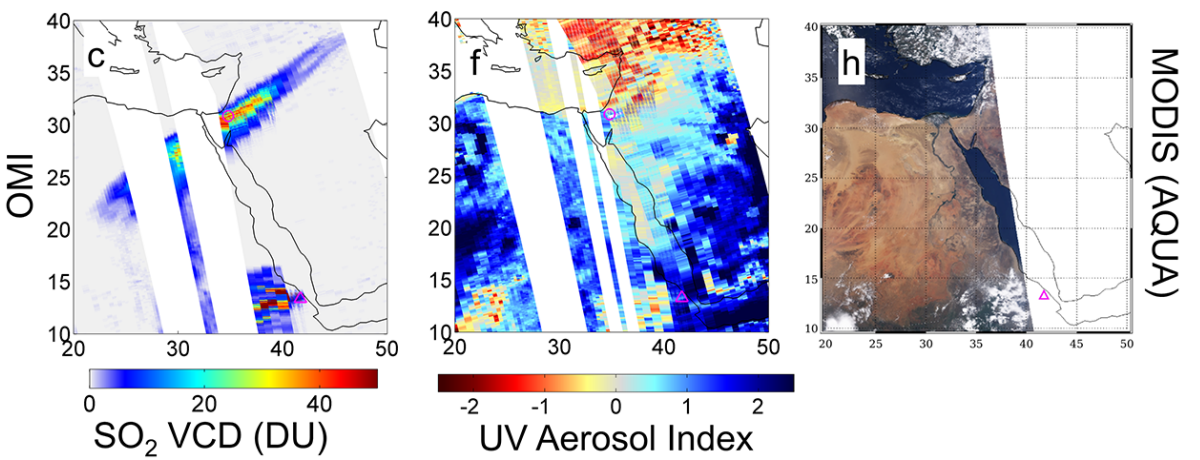

Figure 2. $\mathrm{SO}_{2}$ vertical column density in Dobson Units (panels a-c) and UV Aerosol Index (d-f) from GOME-2 (a and d), SCIAMACHY (b and $\mathbf{e}$ ) and OMI (c and $\mathbf{f})$ and true-colour images from MODIS on TERRA and AQUA ( $\mathbf{g}$ and $\mathbf{h})$ of the region around the Nabro volcano on 14 June 2011. GOME-2 was operating in narrow swath mode. Pink triangles and circles indicate the location of the volcano and of the Sede Boker MPLNET/AERONET station, respectively. The overpass times (UTC) of the different instruments are 07:40 for GOME-2, 08:20 for MODIS-TERRA, 08:50 for SCIAMACHY, 10:00 and 11:40 for OMI and 11:30 for MODIS-AQUA.

The spatial agreement between $\mathrm{SO}_{2}$ and the negative UVAI plume is very good for OMI, but is less clear in the GOME-2 PMD and SCIAMACHY data. Only the later (western) GOME-2 orbit shows a negative UVAI signal coinciding with the $\mathrm{SO}_{2}$ plume, and although UVAI values $<0$ are seen over the full width of the SCIAMACHY swath, the eastern part is probably also affected by clouds (see below). For a more intuitive view of the situation, in panels $g$ and $h$ the true-colour images from the MODIS instruments on TERRA and AQUA, respectively, are given. The time difference between the two sets of instruments is very small; there are $10 \mathrm{~min}$ between SCIAMACHY and MODIS-TERRA overpasses, 75 and 25 min between the two GOME-2 orbits and the MODIS-TERRA overpass, and between OMI and MODIS-AQUA measurements lie $15 \mathrm{~min}$. We assume that the plume has not moved or changed appreciably within such a short time frame.

Most of the particle extinction observed in the MODIS images from 13 June (Fig. 1, panels $\mathrm{g}$ and $\mathrm{h}$ ) is proba- bly due to the presence of ice particles visible in MODIS IR cloud data (Fromm et al., 2013) and in SEVIRI data (Vernier et al., 2013). On the following day, the plume can no longer be seen in MODIS true-colour images (Fig. 2, panels $g$ and $h$ ) and neither is a cloud detected by the IR retrieval (not shown here, but see: http://ladsweb.nascom. nasa.gov/browse_images/granule_browser.html). This does not exclude the possibility that ice was present in the volcanic plume after 13 June, but the low depolarisation ratio detected by CALIOP (Cloud-Aerosol LIdar with Orthogonal Polarisation; Winker et al., 2007) is evidence that it consisted mainly of sulfate aerosols (Vernier et al., 2013; Fairlie et al., 2014; Clarisse et al., 2014). In addition, the overpass of the volcanic plume over the joint MPLNET/AERONET (MicroPulse Lidar NETwork (Welton et al., 2001) and AErosol RObotic NETwork, Holben et al., 1998) site Sede Boker corresponded to a large increase in the number of fine particles (of which the size distribution peaked at approximately $0.1 \mu \mathrm{m}$, see http://aeronet.gsfc.nasa.gov), also clearly indicating that the 

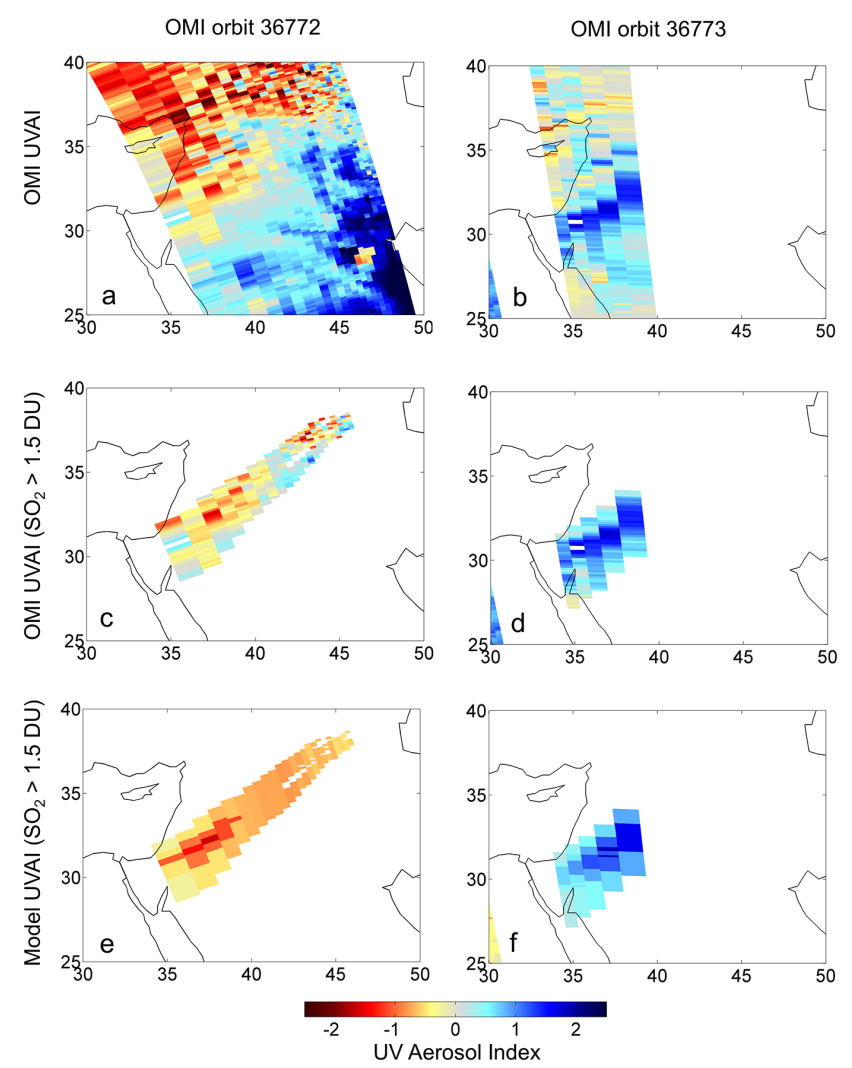

Figure 3. UV Aerosol Index from OMI (panels a-d) and from RTM calculations (e-f) for the volcanic plume detected on 14 June 2011. The left panels (a, c, and e) show data from orbit 36772; on the right (panels b, d, and f) data from the following orbit, 36773, are shown. The data in panels $\mathbf{c}-\mathbf{f}$ are filtered by $\mathrm{SO}_{2}$ vertical column density ( $\geq 1.5 \mathrm{DU}$ ) to more clearly show the volcanic plume. The UVAI in panels (e) and (f) were modelled using McArtim with aerosol parameters representative of sulfate particles at $18-19 \mathrm{~km}$ altitude (see text for details).

plume was made up of sulfate aerosols; the optical depth assigned to coarse-mode particles is very similar to that measured on the days before the eruption and can confidently be attributed to mineral dust. Based on the evidence presented above, we conclude that ice contributed substantially to the negative UVAI signal detected on 13 June, but that the UVAI signal on 14 June was caused by sulfate aerosols.

The $\mathrm{SO}_{2}$ and UVAI data from GOME-2, SCIAMACHY and OMI measured on 14 June are shown in Fig. 2. Only a small part of the $\mathrm{SO}_{2}$ plume was captured by GOME-2 (panel a), because the instrument measured in narrow-swath mode at the time. No sign of sulfate aerosols can be seen in the accompanying UVAI plot d. SCIAMACHY caught the tail end of the volcanic plume (panels b and e): $\mathrm{SO}_{2}$ columns of up to $30 \mathrm{DU}$ were measured and a slightly negative UVAI feature can be seen at the corresponding position in panel e. In the OMI $\mathrm{SO}_{2}$ data displayed in panel $\mathrm{c}$ the first volcanic plume can be seen (over northern Egypt and Israel), but also elevated $\mathrm{SO}_{2}$ columns near the volcano; these were emitted later at lower altitudes and are ignored here. The northern $\mathrm{SO}_{2}$ plume measured by OMI corresponds to an area with clearly negative UVAI values. In panel $f$ the volcanic plume is difficult to separate from the clouds directly to the north. More importantly, the figure does not correctly display all OMI measurements: parts of the two consecutive orbits overlap in the figure, in particular those parts where the sulfate plume is seen. Figure 3 shows both orbits separately, allowing us to focus on an interesting UVAI phenomenon: in the earlier orbit (36772; panels a, c, and e) the high-altitude volcanic plume is viewed from the east, causing it to exhibit negative UVAI values. During the following overpass (orbit 36773; panels b, d, and f), only 100 min later, the viewing direction of the instrument is exactly opposite and positive UVAI are found for the same plume. This is an effect of the phase functions of scattering on air molecules and aerosol particles that can be well reproduced with radiative transfer model (RTM) simulations using McArtim (as detailed in the Supplement). The dependence on viewing geometry is most pronounced for aerosol (or cloud) layers at high altitude (>11 km) and for line-of-sight zenith angles (at the subsatellite point) larger than about $45^{\circ}$, corresponding to the swath edges of OMI. As the clouds directly north of the volcanic plume somewhat muddy the picture, we selected only those pixels that have $\mathrm{SO}_{2}$ columns larger than $1.5 \mathrm{DU}$ for panels $\mathrm{c}$ and d of Fig. 3. Despite the fact that not all selected plume pixels contain a pronounced aerosol signal, the viewing angle effect can be clearly seen. We performed RTM simulations using the aerosol parameters representative of volcanic sulfate particles: $g=0.6$, single-scattering albedo of 1.0 (from Deshler (2008) also used in the limb retrieval) and with an Ångström exponent of 1.5. The maximum aerosol optical thickness (AOT) detected by AERONET is approximately 0.4 (after subtraction of a constant background), therefore we modelled the UVAI from the sulfate plume by assigning an AOT (at $380 \mathrm{~nm}$ ) of 0.4 to those pixels with $\mathrm{SO}_{2}$ column densities exceeding $30 \mathrm{DU}$, an AOT of 0.2 for pixels with $\mathrm{SO}_{2}$ column densities between 15 and $30 \mathrm{DU}$, and an AOT of 0.1 to those with $\mathrm{SO}_{2}$ columns smaller than $15 \mathrm{DU}$. The results of this exercise are shown in panels e and $\mathrm{f}$ of Fig. 3. Although the measurements in panels $\mathrm{c}$ and $\mathrm{d}$ are not in perfect agreement with the model results (which may be due to cloud contamination in orbit 36722 , or inaccuracies in the assumed aerosol parameters), the viewing angle effect is very well reproduced. This leads to two conclusions: (1) the bulk of the volcanic plume must be situated above approximately $11 \mathrm{~km}$, and hence (2) the aerosols must have a high single-scattering albedo $(\geq 0.97)$, or they would not have shown negative UVAI at any viewing angle (see the Supplement for more evidence from RTM calculations). Note that the UVAI caused by clouds directly north of the volcanic plume also changes with viewing angle (compare panels $a$ and $b$ ). The variation in UVAI is not as pronounced as that observed for the volcanic plume because the 

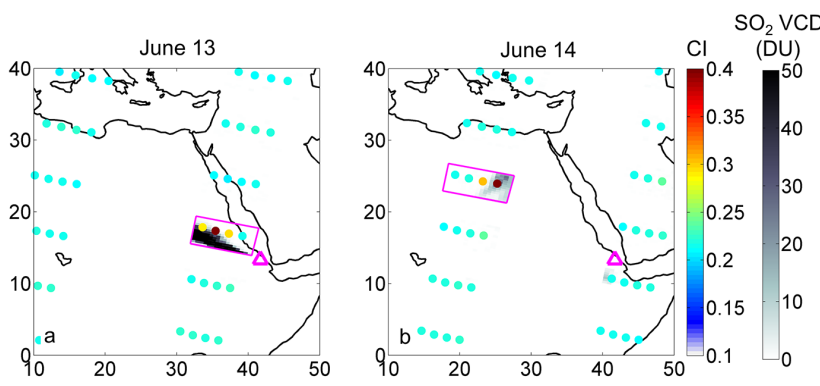

Figure 4. Maps of the SCIAMACHY Colour Index at a tangent height of $18.6 \mathrm{~km}$ for the region around the Nabro volcano on 13 June (panel a) and on 14 June 2011 (b). $\mathrm{SO}_{2}$ columns (in DU) from SCIAMACHY are shown in the background with a grey colour scale. The volcano is marked by a pink triangle; the pink boxes denote the two SCIAMACHY states to which the limb extinction retrieval was applied (Fig. 5).

meteorological clouds are at much lower altitude, but also because the viewing angle dependence of clouds is smaller than that of aerosols (compare Figs. S1 and S2 in the Supplement).

\subsection{SCIAMACHY limb data: colour index and extinction profiles}

Figure 4 shows the centres of SCIAMACHY limb pixels (tangent points) in the region around the Nabro volcano on 13 June (panel a) and 14 June 2011 (b). Each dot is colour coded by the $\mathrm{CI}$ at a TH of $18.6 \mathrm{~km}$, which is clearly above the tropopause (at $16.8 \mathrm{~km}$, according to ECMWF) and is therefore largely unaffected by other scatterers, e.g. cirrus clouds. The only significant enhancements $(\mathrm{CI}>0.25)$ in this region are found very close to the $\mathrm{SO}_{2}$ plume (shown in grey tones) and indicate the presence of an elevated layer of particles.

The extinction profile retrieval was applied to the two SCIAMACHY states marked by pink boxes in Fig. 4. Whereas the four limb pixels within the selected state from June 13 all detect the aerosol plume (CI $>0.25)$, the tangent points of the first two (western) limb pixels on 14 June lie outside of the volcanic plume and can be regarded as background measurements. The extinction profiles for all selected pixels are shown in Fig. 5. To avoid cluttered plots, the retrieved extinction is depicted as a point at a certain altitude, whereas in reality the value represents the extinction for a $3 \mathrm{~km}$ high box centred at the respective TH. Note that the $3 \mathrm{~km}$ vertical resolution of SCIAMACHY (along with 3-D effects that will be introduced shortly) causes the retrieved aerosol layer to appear much broader than the actual plume. The profiles for the two scenes outside of the volcanic plume (pixels 1 and 2 in panel $\mathrm{b}$, and marked as background 1 and 2 in panel a) are very similar, reaching a maximum of $1 \times 10^{-4} \mathrm{~km}^{-1}$, corresponding to the stratospheric background aerosol layer (SPARC, 2006). All non-background
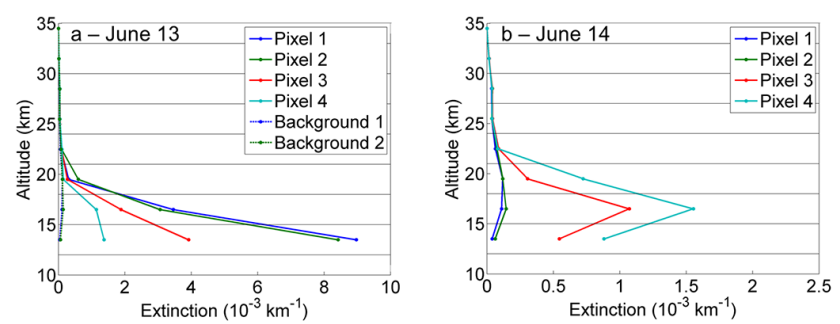

Figure 5. Limb extinction profiles of all limb pixels in the SCIAMACHY state containing parts of the $\mathrm{SO}_{2}$ plume on 13 June (state 20 of orbit 48555; panel a) and on 14 June 2011 (state 19 of orbit 48570; panel b). The resolution of the instrument is indicated by the black grid lines. The two profiles labelled "Background" (dashed lines in panel a) are the profiles from pixels 1 and 2 on 14 June (panel b). Note that the panels have different $x$-axis scales. Pixel enumeration is from West to East.

pixels in panel a (13 June, orbit 48555 , state 20 ), on the other hand, show enhanced particle extinction from $19.5 \mathrm{~km}$ down to $13.5 \mathrm{~km}$, with a maximum of $4.4 \times 10^{-3} \mathrm{~km}^{-1}$ at $13.5 \mathrm{~km}$. In comparison, pixels 3 and 4 in panel b (14 June, orbit 48570 , state 19) show a smaller extinction maximum $\left(<1.4 \times 10^{-3} \mathrm{~km}^{-1}\right)$ and a profile that is shifted to higher altitude, with a pronounced peak at $16.5 \mathrm{~km}$.

The retrieval leading to the results shown in Fig. 5 was performed under the assumption of a homogeneous aerosol layer of $3 \mathrm{~km}$ thickness, spreading out infinitely in the horizontal plane through the tangent point (TP). This assumption is usually justified for stratospheric background aerosols, but not for the volcanic plume studied here, as illustrated in Fig. 6. Not only are the plume dimensions (indicated by the grey shaded nadir $\mathrm{SO}_{2}$ data) finite; the plume is also not located symmetrically around the TPs (approximate positions marked by yellow numbers). As a result, both the retrieved extinction and the layer altitude are affected. The effects of observing an aerosol plume (or cloud) with finite dimensions can be intuitively understood by studying the lines-of-sight of the limb instrument at various THs (solid black lines in Fig. 7). The infinite aerosol layer assumed in the retrieval is depicted in green in panel a. If the retrieval algorithm is applied to a finite aerosol layer (panel b), the extinction is underestimated, because the retrieval "expects" the plume to have an infinite horizontal extent. If, in addition, the layer is positioned off-centre with respect to the TP (panel c), both the extinction and the altitude of the layer are underestimated: the aerosol layer is mainly located within the lineof-sight at $13.5 \mathrm{~km}$, therefore the retrieval algorithm wrongly places the extinction at that altitude. The magnitude of the underestimation of aerosol layer altitude depends on the distance to the TP. Taking the limb lines-of-sight into account leads to the TH-dependent sensitivity areas depicted in Fig. 6 for observations with $\mathrm{TH}=16.5 \mathrm{~km}$. If an aerosol plume at $15-18 \mathrm{~km}$ of finite width were to be located only within the blue boxes, the retrieval algorithm would (correctly) assign 

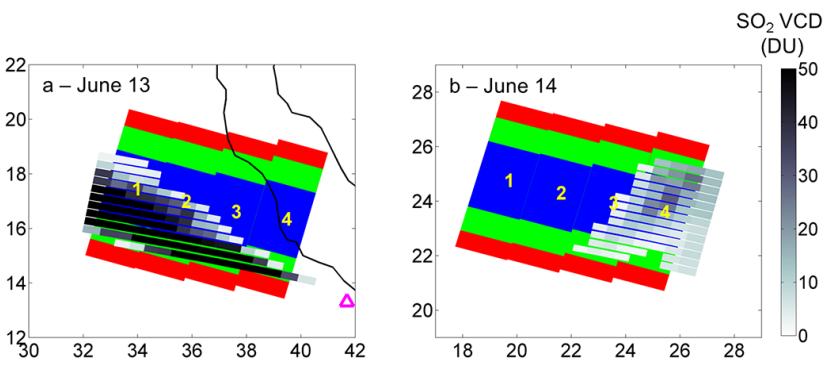

Figure 6. Areas contributing to the limb signal at $\mathrm{TH}=16.5 \mathrm{~km}$ (blue), $\mathrm{TH}=13.5 \mathrm{~km}$ (green), and $\mathrm{TH}=10.5 \mathrm{~km}$ (red) for a homogeneous, infinite aerosol layer located at $15-18 \mathrm{~km}$ altitude. SCIAMACHY $\mathrm{SO}_{2}$ columns (grey colour scale; only values $>2 \mathrm{DU}$ are shown) are plotted to indicate the extent of the volcanic plume on 13 June (panel a) and 14 June (b). The limb pixel numbers are shown in yellow at their respective TPs.

the extinction to $16.5 \mathrm{~km}$. If, on the other hand, the plume were confined to the green or even red regions, an altitude of 13.5 or $10.5 \mathrm{~km}$ would be retrieved. Similar displacements are found for observations at other THs. Note that the retrieval algorithm can lead to a significant underestimation of aerosol layer altitude, but never to an overestimation. These effects cannot easily be corrected for in our retrieval algorithm, due to e.g. the necessity to define a non-localised background aerosol in addition to the localised volcanic aerosol in the retrieval. We are investigating these so-called 3-D effects in more detail and will publish the results and a more detailed description of the algorithm in a manuscript dedicated to the limb retrieval; an earlier version was presented in Dörner et al. (2012).

In view of the above, the fact that the volcanic plume is located somewhat off-centre on 13 June (particularly for pixel 4) may be the explanation for the west-to-east (pixels 1-4) decrease in extinction observed on 13 June - although the decrease may also be physical. The exceptionally high extinction retrieved for 13 June (in comparison to extinctions determined for 14-17 June) almost certainly results from the ice cloud, mentioned in Sect. 4.1, of which the top was at an altitude of $19.5 \mathrm{~km}$, according to SEVIRI data (Vernier et al., 2013). The SCIAMACHY limb retrieval detects the ice cloud at slightly lower altitude (possibly due to the fact that the cloud is not centred at the TP) and is of such high optical density that the limb retrievals below the maximum (at $16.5 \mathrm{~km}$ ) are affected and probably yield extinctions that are unrealistically high. Only for optically very thin aerosol layers, such as the volcanic plume shown in panel b of Fig. 5, can both plume top and bottom be retrieved. On the other hand, lowerlying aerosols (such as those detected by the MPLNET lidar at Sede Boker) may also be the cause of the increased extinction at $13.5 \mathrm{~km}$ in panel a.

\subsection{Transport and evolution of the volcanic plume}

The first volcanic plume from Nabro could be distinctively seen in GOME-2, SCIAMACHY and OMI data until 17 June, when overlap with the plumes from various later explosions no longer allowed a clear attribution of the emission time (Fig. 8). Although the $\mathrm{SO}_{2}$ plumes detected on 15 June overlap in the horizontal plane (best seen in panel a between $\left.40-70^{\circ} \mathrm{E}\right)$, the difference in plume altitude and resulting differences in wind speed and direction ensure that the two plumes can be observed separately again on 16 and 17 June. The first, stratospheric, plume takes a more northerly route than the lower-lying tropospheric plume, as can be seen in the $\mathrm{SO}_{2}$ data and is confirmed by measurements from the CALIOP lidar on board the CALIPSO satellite (Fairlie et al., 2014). CALIOP first detected the stratospheric aerosol layer from Nabro at $16-18 \mathrm{~km}$ altitude at about 22:40 UTC on 15 June (Vernier et al., 2013; Fairlie et al., 2014) and at altitudes between $16-18 \mathrm{~km}$ during at least five overpasses on 16 June. The ground track of one overpass (at 09:46 UTC) is exemplarily shown in red in panel h of Fig. 8. During this particular overpass, two elevated aerosol layers were detected: one at $11 \mathrm{~km}$ (cross and arrow labelled "t") and an optically thicker one at $17 \mathrm{~km}$ (circles and arrow labelled "s") corresponding to the locations of the tropospheric plume and the (northern) stratospheric plume, respectively.

We retrieved the limb extinction profiles from the SCIAMACHY states covering the first volcanic plume, using $\mathrm{SO}_{2}$ column density in the corresponding nadir pixels as a proxy for the location and spread of the plume. The resulting extinction profiles from all 18 states can be found in the Supplement; in Fig. 9, we show only a selection of six sets of profiles. The corresponding (nadir) states are marked by pink boxes and labels (a-f) in Fig. 8, panels b, e, and h. The first pixel of state 17 of orbit 48584 on 15 June (blue line and dots in panel a) shows an extinction profile that is close to the background profile, but shows enhanced aerosol extinction at $16.5 \mathrm{~km}$ and below. This can probably be attributed to the part of the stratospheric aerosol plume that lies just south of the nadir state - the fact that the plume is far off the TP leads to the underestimation of both extinction and plume altitude (Sect. 4.2). Pixels 2-4, on the other hand, clearly see the plume: the maximum extinction, reached at $16.5 \mathrm{~km}$, is $1-1.3 \times 10^{-3} \mathrm{~km}^{-1}$. One orbit earlier (panel b), the stratospheric plume is clearly seen in pixels $2-4$ of state 16 , but because the major part of the plume lies south of the TPs, we expect the extinction and altitude to be underestimated. Underlying clouds might be the reason that no clear extinction maximum is found. Figure S3 in the Supplement shows the corresponding effective cloud fractions from the FRESCO+ (Fast Retrieval Scheme for Clouds from the Oxygen A-band) algorithm (Wang et al., 2008). On 16 June, the stratospheric plume fills the width of both SCIAMACHY state 16 (orbit 48598) and state 17 (orbit 48597). In the former (panel c), extinction maxima of $7-9 \times 10^{-3} \mathrm{~km}^{-1}$ are found at $16.5 \mathrm{~km}$. 


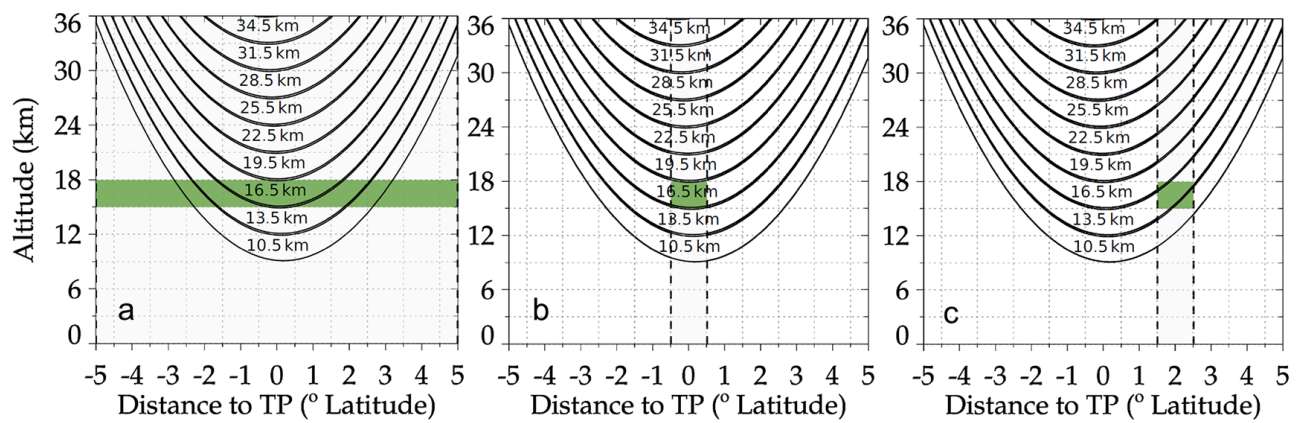

Figure 7. Schematics of the lines-of-sight of SCIAMACHY limb geometry. The current limb retrieval assumes an infinite, homogeneous aerosol layer centred at the TH (green layer in panel a). If aerosols are localised (b), extinction is underestimated; if the plume is additionally not centred at the tangent point TP (c), both extinction and plume altitude are underestimated. See the text for further details.
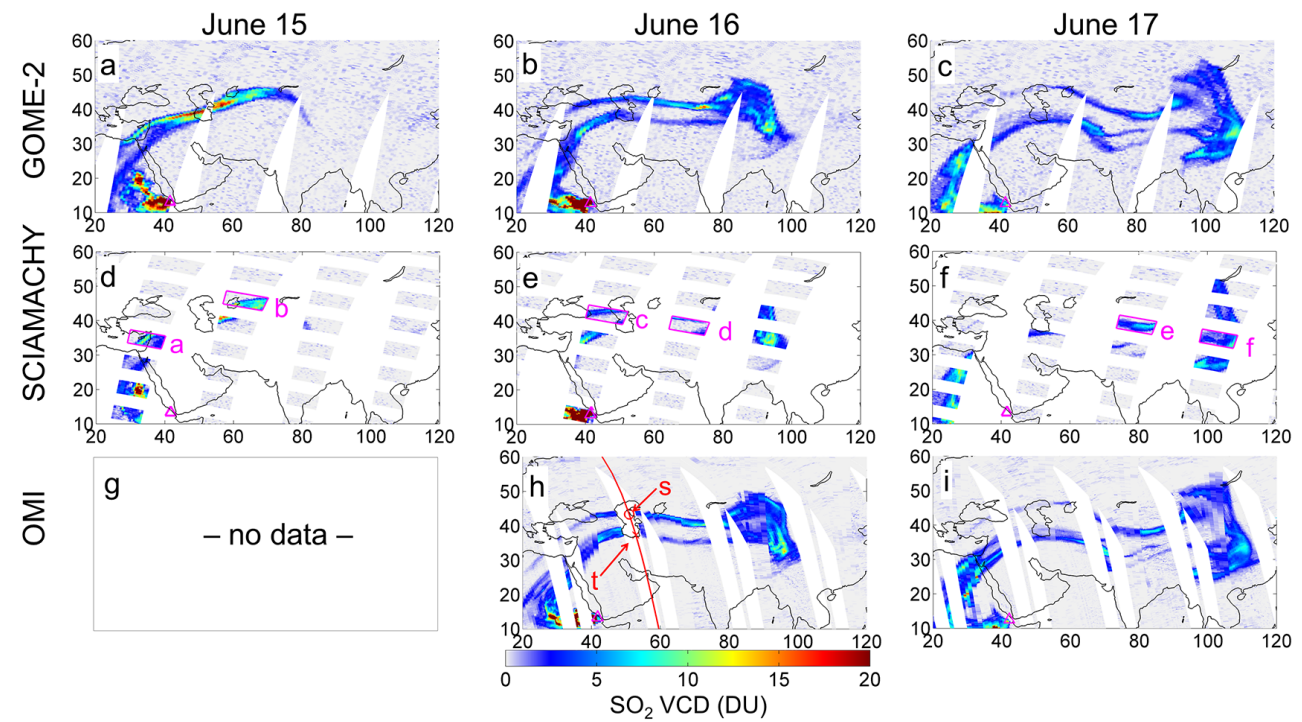

Figure 8. $\mathrm{SO}_{2}$ time series from GOME-2 (panels a-c in the upper row), SCIAMACHY (d-f; centre), and OMI (g-i; lower row). Measurements from 15 June (left), 16 June (centre) and 17 June 2011 (right) are shown. There are no measurements available from OMI on 15 June. The extinction profiles from the states marked by labelled pink boxes are shown in the corresponding panels of Fig. 9. The red line indicates the ground track of one (near-simultaneous) CALIPSO orbit; the red symbols and arrows mark the locations of tropospheric (" $\mathrm{t}$ ", cross) and stratospheric ("s", circles) aerosol layers detected by CALIOP.

The plume is located further from the TPs of pixels 1 and 4 , which translates into a downward shift of the retrieved profiles relative to those of pixels 2 and 3: the retrieved extinction at $19.5 \mathrm{~km}$ is significantly higher in pixels 2 and 3 . Another explanation could be that the plume detected in pixels 2 and 3 reaches a higher altitude, but this seems less plausible - particularly because the nadir $\mathrm{SO}_{2}$ data support the first explanation (Fig. 8, panel e). In the latter (panel d), the plume is clearly off-centre, again causing an underestimation of plume altitude (as seen when comparing to pixels 2-3 in panel c) and extinction. The increased extinction found at lower altitude in pixel 4 may originate from the tropospheric plume, glimpsed in the southeastern corner of the state. The extinction profiles from state 17 , orbit 48611, measured on 17 June (panel e), look very similar to those shown in panel c: in all pixels strongly enhanced aerosol extinction with maxima of $0.7-1.0 \times 10^{-3} \mathrm{~km}^{-1}$ at $16.5 \mathrm{~km}$ are found; in pixels 3 and 4, where the highest nadir $\mathrm{SO}_{2}$ columns are found, aerosol extinction exceeds $0.6 \times 10^{-3} \mathrm{~km}^{-1}$ even at $19.5 \mathrm{~km}$. The variability of retrieved aerosol extinction at the lowest altitude of $13.5 \mathrm{~km}$ may be due to the underlying clouds. FRESCO+ detected clouds at an altitude of about $4 \mathrm{~km}$ in the nadir pixels corresponding to limb pixels 1, 3 and 4 and clouds at $7-8 \mathrm{~km}$ in limb pixel 2. Interpreting the results from the aerosol retrieval from state 17 , orbit 48610 (panel f) is not straightforward, in particular because we can no longer be guided by the $\mathrm{SO}_{2}$ measurements due to the overlap of the first plume from Nabro and later emissions. The stratospheric plume is still clearly present, as seen by the enhanced particle extinction at $16.5 \mathrm{~km}$, but underlying clouds and (possibly) 

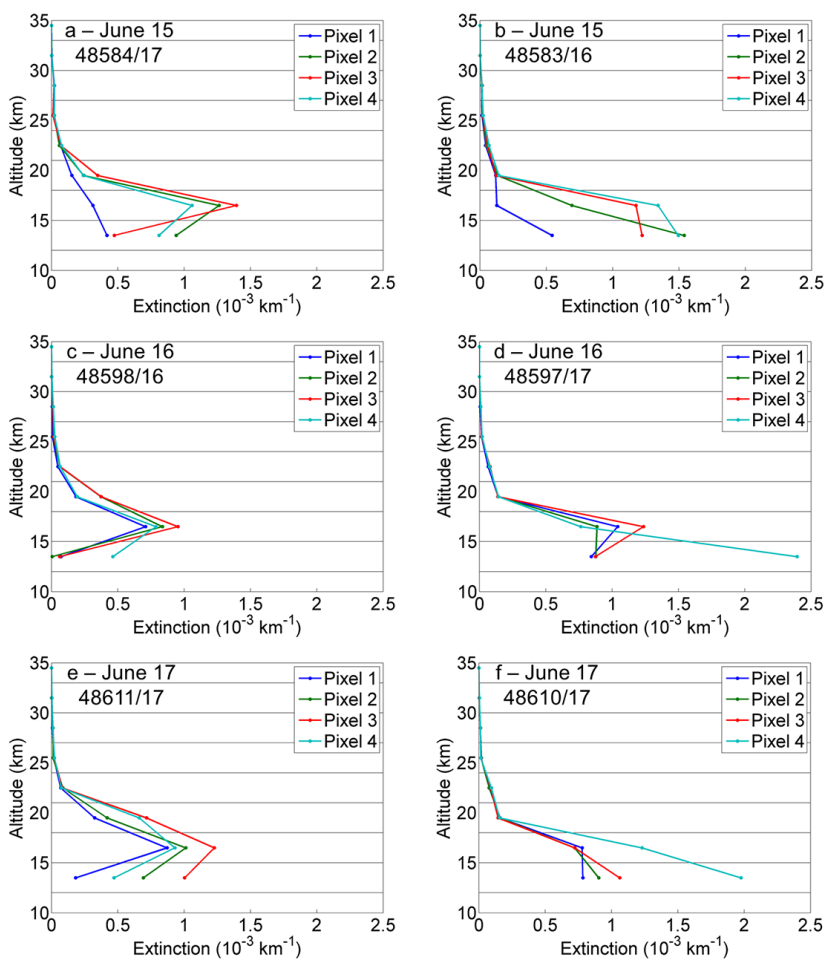

Figure 9. Limb extinction profiles of all limb pixels within the pink boxes in Fig. 8. First row (15 June): (a) orbit 48584, state 17; (b) orbit 48583, state 16. Second row (16 June): (c) orbit 48598, state 16; (d) orbit 48597, state 17. Third row (17 June): (e) orbit 48611, state 17; (f) orbit 48610 , state 17 . Pixel enumeration is from West to East.

lower-lying volcanic aerosol layers cause the retrieval of high extinctions down to $13.5 \mathrm{~km}$.

\section{Discussion}

We have presented evidence that the eruption of Nabro on 12/13 June 2011 caused the injection of sulfate aerosols into the stratosphere. Using a new SCIAMACHY limb retrieval algorithm, the extinction profile could be determined for parts of the volcanic plume on every day of 13-17 June. The aerosol plume was simultaneously detected in nadir by UVAI from SCIAMACHY and (with a small time difference) from GOME-2 and OMI on 13 and 14 June. We discuss the presented results in the following sections.

\subsection{Sulfate aerosols}

The major part of stratospheric $\mathrm{SO}_{2}$ from Nabro was probably converted to sulfate on the timescale of weeks (Bourassa et al., 2012), yet we showed that an amount large enough to be detected from satellites was formed within hours of the eruption. Using the UVAI, similar results were found for volcanic eruptions in the past, e.g. Hekla in 2000 (Rose et al., 2003), Soufrière Hills and Nyamuragira in 2006, Okmok and Kasatochi in 2008, and Sarychev Peak in 2009 (unpublished results). Rapid sulfate formation was also observed in the young eruption plume of Pinatubo in 1991 (Guo et al., 2004), indicating that in this sense, the Nabro eruption was not unique.

Although there were reports of ash fallout near the volcano (Smithsonian Institution, 2011), no evidence of ash particles within the volcanic plume is seen either in the true-colour images or in the UVAI plots. UVAI are very sensitive to absorbing particles, particularly if they are elevated, hence even a relatively small amount of ash would cause UVAI to increase to near zero, or even positive values. Positive UVAI values (blue tones) are seen in most of the satellite pixels not covered by clouds or the $\mathrm{SO}_{2}$ plume and could, in principle, be caused by volcanic ash. But the presence of elevated dust, clearly seen over the Red Sea in panels $g$ and $h$ of Fig 1, makes this a very unlikely attribution.

The effect of the ice cloud on UVAI is potentially substantial, but is difficult to quantify due to the complications regarding the modelling of ice clouds. RTM calculations have shown that cloud droplets cannot cause UVAI values much lower than -1 (ice, Rose et al., 2003) or -1.5 (liquid cloud droplets, Penning de Vries and Wagner, 2011). Nevertheless, in Penning de Vries and Wagner (2011) UVAI values $\ll 1.5$ were regularly found in cloudy scenes, which could not be explained using RTM calculations. In fact, the same phenomenon is observed in Fig. 1 (panels d-f), where strongly negative UVAI are found over clouded regions on the northern edge of the figure and directly south of the volcanic plume, and in Fig. 2 (panels e and f), where clouds cause negative UVAI to the north of the plume. Given the present data set and knowledge, it is not possible to say if the ice cloud merely enhances the UVAI signal from the sulfate plume or if the strong negative UVAI signals are caused by the ice cloud itself. Yet, a negative UVAI signal corresponding to the $\mathrm{SO}_{2}$ plume can be discerned in SCIAMACHY and OMI UVAI data on 14 June, albeit much weaker, as shown in Fig. 2 (panels e and f), whereas there is no indication of ice particles in MODIS visible or IR data (as mentioned in Sect. 4.1). Apart from the limb data, the most clear evidence that sulfate aerosols were detected by the UVAI comes from OMI, where the strong viewing angle dependence of UVAI indicates the presence of a high-altitude $(>11 \mathrm{~km})$ aerosol plume with very high single-scattering albedo $(>0.97)$. We note that due to the slightly different definitions of UVAI, the viewing angle dependence is not the same for the three available OMI UVAI products (OMAERUV, OMAERO and OMTO3). The strong viewing angle dependence complicates the interpretation of UVAI, but could be turned into an advantage with regard to the determination of aerosol properties. For elevated aerosol plumes large enough to cover the entire OMI swath, or plumes captured twice by OMI from opposing viewing angles (as in the case of the Nabro plume on 14 June) the viewing angle dependence can be exploited to determine the 
aerosol absorption and plume altitude. This approach can be applied to volcanic plumes, as shown here, but potentially also to extensive smoke or elevated pollution plumes. We are currently investigating the viewing angle dependence of UVAI in more detail using RTM calculations and OMI UVAI data.

\subsection{Extinction profiles}

One of the most challenging aspects of limb retrievals is determining where (the major part of) the detected signal comes from. For an optically thin atmosphere the tangent point is a good approximation, but the situation is more complex when an optically thick layer (e.g. a volcanic plume) affects the pathways of photons through the atmosphere. As shown in Figs. 6 and 7, the extinction and altitude of an aerosol layer can be severely underestimated (though not overestimated) if the spatial dimensions and the placement of the layer are not properly accounted for. Tests with model data point at a linear relationship between relative error in retrieved extinction and the "area" that the aerosol layer covers within the total line-of-sight (indicated in green in Fig. 7). The retrieved altitude can be underestimated by several kilometres depending on the position of the aerosol layer with respect to the TP, as demonstrated in Figs. 6 and 7. Similar effects are expected for the colour index (ratio) and should be kept in mind when aerosol plumes or clouds (e.g. polar stratospheric clouds) of finite dimensions are the object of studies involving limb data.

During its overpass over the MPLNET (MicroPulse Lidar NETwork, Welton et al., 2001) station in Sede Boker, Israel, the AOT of Nabro's first volcanic plume was determined to be 0.17 by lidar measurements at $532 \mathrm{~nm}$ (Sawamura et al., 2012). When we integrate the profiles shown in Figs. 5 and 9, much smaller values of AOT are found, e.g. $8 \times 10^{-3}$ for the profile of pixel 4 on 14 June, or $5 \times 10^{-3}$ for pixel 3 from orbit 48584 on 15 June. The difference can be attributed to three effects. First, judging by the shape and column density of the $\mathrm{SO}_{2}$ plume, the measured part of the plume (on 16 June) is not very dense in comparison with the middle of the plume, where the MPLNET AOT was measured. This is confirmed by CALIOP measurements from the orbit shown in Fig. 8, where an AOT of 0.03 is found for an aerosol layer at $16-17 \mathrm{~km}$ altitude (at $532 \mathrm{~nm}$; assuming small particles, this corresponds to about 0.02 at $750 \mathrm{~nm}$ ). Second, the finite dimensions of the plume cause the extinction from the limb retrieval to be on the order of a factor of 2 too low. Third, the retrieved extinction depends on the aerosol optical parameters assumed in the RTM calculations. Taking into account retrieval errors of CALIOP data (the uncertainty in extinction at $523 \mathrm{~nm}$ is given as 0.02), the agreement between SCIAMACHY limb measurements and satellite-borne lidar measurements is well within the uncertainty range.

\subsection{Concluding remarks}

Using nadir $\mathrm{SO}_{2}$ and UVAI measurements from SCIAMACHY, GOME-2 and OMI, and limb measurements from SCIAMACHY we were able to detect sulfate aerosols in the stratosphere within the first volcanic plume from Nabro in the 5 days (13-17 June 2011) following the eruption. The bulk of the aerosol layer was found at $15-20 \mathrm{~km}$ by the limb retrieval; detailed analysis of nadir UVAI from OMI provided evidence for the non-absorbing nature of the particles (single-scattering albedo $>0.97$ ). We found that the viewing angle dependence of UVAI from high-altitude plumes can be large enough to change the sign of UVAI, which complicates the interpretation of UVAI, but also provides an opportunity to determine aerosol properties within extensive aerosol plumes. In addition, we have shown that if the dimensions and the position of an aerosol plume (with respect to the tangent point) are not properly taken into account in the limb aerosol retrieval algorithm, both the retrieved extinction and layer height may be affected appreciably. In conclusion, the combination of nadir trace gas and aerosol data with profile information from limb measurements is well suited to study the characteristics of a high-altitude volcanic plume. Although SCIAMACHY is now lost, this type of analysis (at least for volcanic plumes) could be continued using an instrument like the Ozone Mapping and Profiling Suite (OMPS) on Suomi-NPP (NPOESS Preparatory Project, where NPOESS stands for National Polar-orbiting Environmental Satellite System), which similarly measures $\mathrm{SO}_{2}$ and UVAI in nadir and has limb-viewing capabilities.

\section{The Supplement related to this article is available online at doi:10.5194/acp-14-8149-2014-supplement.}

Acknowledgements. We gratefully acknowledge the use of the following Level-2 data products: calibrated MODIS radiances, OMI OMAERUV UVAI, and CALIOP extinction profiles from NASA; SCIAMACHY and GOME-2 UVAI (within the O3MSAF) and FRESCO+ cloud fractions from TEMIS, with special thanks to Olaf Tuinder for GOME-2 UVAI from PMDs. EUMETSAT is acknowledged for providing Level-1 data from SCIAMACHY and GOME-2 and NASA for Level-1 OMI data. ECMWF Reanalysis data used in this study have been obtained from the ECMWF Data Server. We thank the MPLNET and AERONET teams (Arnon Karnieli) at Sede Boker for sharing their data and maintaining the measurement site. S. Beirle, S. Kühl, L. Clarisse, N. Theys, K. Yang and M. von Hobe are thanked for stimulating discussions. One of the authors (J. Puksite) is funded by the Deutsche Forschungsgemeinschaft (PU518/1-1).

The service charges for this open access publication have been covered by the Max Planck Society.

Edited by: A. Stohl 


\section{References}

Bobrowski, N. and Platt, $\mathrm{U} .: \mathrm{SO}_{2} / \mathrm{BrO}$ ratios studied in five volcanic plumes, J. Volcanol. Geoth. Res., 166, 147-160, doi:10.1016/j.jvolgeores.2007.07.003, 2007.

Bobrowski, N., Kern, C., Platt, U., Hörmann, C., and Wagner, T.: Novel $\mathrm{SO}_{2}$ spectral evaluation scheme using the 360 $390 \mathrm{~nm}$ wavelength range, Atmos. Meas. Tech., 3, 879-891, doi:10.5194/amt-3-879-2010, 2010.

Bovensmann, H., Burrows, J. P., Buchwitz, M., Frerick, J., Noël, S., Rozanov, V. V., Chance, K. V., and Goede, A. P. H.: SCIAMACHY: Mission objectives and measurement modes, J. Atmos. Sci., 56, 127-150, 1999.

Bluth, G. J. S., Schnetzler, C. C., Krueger, A. J., and Walter, L. S.: The contribution of explosive volcanism to global atmospheric sulphur dioxide concentrations, Nature, 366, 327-329, 1993.

Bluth, G. J. S., Rose, W. I., Sprod, I. E., and Krueger, A. J.: Stratospheric loading of sulfur from explosive volcanic eruptions, J. Geol., 105, 671-683, 1997.

Bourassa, A. E., Robock, A., Randel, W. J., Deshler, T., Rieger, L. A., Lloyd, N. D., Llewellyn, E. J., and Degenstein, D. A.: Large volcanic aerosol load in the stratosphere linked to Asian monsoon transport, Science, 337, 78-81, 2012.

Callies, J., Corpaccioli, E., Eisinger, M., Hahne, A., and Lefebvre, A.: GOME-2 - MetOp's second generation sensor for operational ozone monitoring, ESA Bull., 102, 28-36, 2000.

Clarisse, L., Coheur, P.-F., Theys, N., Hurtmans, D., and Clerbaux, C.: The 2011 Nabro eruption, a $\mathrm{SO}_{2}$ plume height analysis using IASI measurements, Atmos. Chem. Phys., 14, 3095-3111, doi:10.5194/acp-14-3095-2014, 2014.

Constantine, E. K., Bluth, G. J. S., and Rose, W. I.: TOMS and AVHRR Observations of Drifting Volcanic Clouds From the August 1991 Eruptions of Cerro Hudson, AGU Monograph 116 - Remote Sensing of Active Volcanism, edited by: Mouginis-Mark, P., Crisp, J., and Fink, J., 45-64, doi:10.1029/2004JD005178, 2000.

de Graaf, M., Stammes, P., Torres, O., and Koelemeijer, R. B. A.: Absorbing Aerosol Index - Sensitivity analysis, application to GOME and comparison with TOMS, J. Geophys. Res., 110, D01202, doi:10.1029/2004JD005178, 2005.

de Graaf, M., Tuinder, O., Tilstra, G., and Penning de Vries, M.: Algorithm Theoretical Basis Document for the GOME-2 Aerosol products, O3MSAF/KNMI/ATBD/002, 2.1, EUMETSAT, 2013.

Deshler, T.: A review of global stratospheric aerosol: Measurements, importance, life cycle, and local stratospheric aerosol, J. Atmos. Res., 90, 223-232, doi:10.1016/j.atmosres.2008.03.016, 2008.

Deutschmann, T., Beirle, S., Frieß, U., Grzegorski, M., Kern, C., Kritten, L., Platt, U., Prados-Roman, C., Puķīte, J., Wagner, T., Werner, B., and Pfeilsticker, K.: The Monte Carlo atmospheric radiative transfer model McArtim: Introduction and validation of Jacobians and 3D features, J. Quant. Spectrosc. Ra., 112, 11191137, 2011.

Dörner, S., Puķīe, J., Kühl, S., Penning de Vries, M., and Wagner, T.: Retrieval of stratospheric aerosol properties from SCIAMACHY limb observations, in: Proceedings of the ESA conference "Living Planet", 9-13 September 2013, SP-482 (CDROM), Edinburgh, UK, 2013.
Eisinger, M. and J. P. Burrows, Tropospheric sulfur dioxide observed by the ERS-2 GOME instrument, Geophys. Res. Lett., 25, 4177-4180, 1998.

Enell, C.-F., Steen, Å., Wagner, T., Frieß, U., Pfeilsticker, K., Platt, U., and Fricke, K.-H.: Occurrence of polar stratospheric clouds at Kiruna, Ann. Geophys., 17, 1457-1462, doi:10.1007/s00585999-1457-7, 1999.

Ernst, F., von Savigny, C., Rozanov, A., Rozanov, V., Eichmann, K.-U., Brinkhoff, L. A., Bovensmann, H., and Burrows, J. P.: Global stratospheric aerosol extinction profile retrievals from SCIAMACHY limb-scatter observations, Atmos. Meas. Tech. Discuss., 5, 5993-6035, doi:10.5194/amtd-5-5993-2012, 2012.

Fairlie, T. D., Vernier, J.-P., Natarajan, M., and Bedka, K. M.: Dispersion of the Nabro volcanic plume and its relation to the Asian summer monsoon, Atmos. Chem. Phys., 14, 7045-7057, doi:10.5194/acp-14-7045-2014, 2014.

Fromm, M., Lindsey, D. T., Servranckx, R., Yue, G., Trickl, T., Sica, R., Doucet, P., and Godin-Beekmann, S.: The untold story of pyrocumulonimbus, B. Am. Meteorol. Soc., 91, 1193-1209, 2010.

Fromm, M., Nedoluha, G., and Charvát, Z.: Comment on 'Large volcanic aerosol load in the stratosphere linked to Asian monsoon transport", Science, 339, 647, 2013.

Galle, B., Oppenheimer, C., Geyer, A., McGonigle, A. J., Edmonds, M., and Horrocks, L.: A miniaturised ultraviolet spectrometer for remote sensing of $\mathrm{SO}_{2}$ fluxes: a new tool for volcano surveillance, J. Volcanol. Geoth. Res., 119, 241-254, doi:10.1016/S0377-0273(02)00356-6, 2003.

Gottwald, M. and Bovensmann, H.: SCIAMACHY - Exploring the Changing Earth's Atmosphere, Springer, Dordrecht, Heidelberg, London, New York, 2011.

Grzegorski, M., Wenig, M., Platt, U., Stammes, P., Fournier, N., and Wagner, T.: The Heidelberg iterative cloud retrieval utilities (HICRU) and its application to GOME data, Atmos. Chem. Phys., 6, 4461-4476, doi:10.5194/acp-6-4461-2006, 2006.

Guo, S., Rose, W. I., Bluth, G. J. S., and Watson, I. M.: Particles in the great Pinatubo volcanic cloud of June 1991: The role of ice, Geochem. Geophy. Geosy., 5, Q05003, doi:10.1029/2003GC000655, 2004.

Hansen, J., Lacis, A., Ruedy, R., and Sato, M.: Potential climate impact of Mount Pinatubo eruption, Geophys. Res. Lett., 19, 215 218, 1992.

Haywood, J. M., Jones, A., Clarisse, L., Bourassa, A., Barnes, J., Telford, P., Bellouin, N., Boucher, O., Agnew, P., Clerbaux, C., Coheur, P., Degenstein, D., and Braesicke, P.: Observations of the eruption of the Sarychev volcano and simulations using the HadGEM2 climate model, J. Geophys. Res., 115, D21212, doi:10.1029/2010JD014447, 2010.

Herman, J. R., Bhartia, P. K., Torres, O., Hsu, C., Seftor, C., and Celarier, E.: Global distribution of UV-absorbing aerosols from Nimbus 7/TOMS data, J. Geophys. Res., 102, 16911-16922, 1997.

Hofmann, D. J. and Solomon, S.: Ozone destruction through heterogeneous chemistry following the eruption of El Chichón, J. Geophys. Res., 94, 5029-5041, 1989.

Holben B. N., Eck, T. F., Slutsker, I., Tanre, D., Buis, J. P., Setzer, A., Vermote, E., Reagan, J. A., Kaufman, Y., Nakajima, T., Lavenu, F., Jankowiak, I., and Smirnov, A.: AERONET - A federated instrument network and data archive for aerosol characterization, Remote Sens. Environ., 66, 1-16, 1998. 
Hörmann, C., Sihler, H., Bobrowski, N., Beirle, S., Penning de Vries, M., Platt, U., and Wagner, T.: Systematic investigation of bromine monoxide in volcanic plumes from space by using the GOME-2 instrument, Atmos. Chem. Phys., 13, 4749-4781, doi:10.5194/acp-13-4749-2013, 2013.

Hsu, N. C., Herman, J. R., Gleason, J. F., Torres, O., and Seftor, C. J.: Satellite detection of smoke aerosols over a snow/ice surface by TOMS, Geophys. Res. Lett., 26, 1165-1168, 1999.

Kirchner, I., Stenchikov, G. L., Graf, H.-F., Robock, A., and Antuña, J. C.: Climate model simulation of winter warming and summer cooling following the 1991 Mount Pinatubo eruption, J. Geophys. Res., 104, 19039-19055, 1999.

Khokhar, M. F., Frankenberg, C., Van Roozendael, M., Beirle, S., Kühl, S., Richter, A., Platt, U., and Wagner, T.: Satellite observations of atmospheric $\mathrm{SO}_{2}$ from volcanic eruptions during the time-period of 1996-2002, Adv. Space Res., 36, 879-887, doi:10.1016/j.asr.2005.04.114, 2005.

Krijger, J. M., van Weele, M., Aben, I., and Frey, R.: Technical Note: The effect of sensor resolution on the number of cloud-free observations from space, Atmos. Chem. Phys., 7, 2881-2891, doi:10.5194/acp-7-2881-2007, 2007.

Krotkov, N. A., Schoeberl, M. R., Morris, G. A., Carn, S., and Yang, K.: Dispersion and lifetime of the $\mathrm{SO}_{2}$ cloud from the August 2008 Kasatochi eruption, J. Geophys. Res., 115, D00L20, doi:10.1029/2010JD013984, 2010.

Levelt, P. F., van den Oord, G. H. J., Dobber, M. R., Mälkki, A., Visser, H., de Vries, J., Stammes, P., Lundell, J., and Saari, H.: The Ozone Monitoring Instrument, IEEE T. Geosci. Remote, 44, 1093-1101, doi:10.1109/TGRS.2006.872333, 2006.

McCormick, M. P., Thomason, L. W., and Trepte, C. R.: Atmospheric effects of the Mt Pinatubo eruption, Nature, 373, 399404, 1995.

Ovigneur, B., Landgraf, J., Snel, R., and Aben, I.: Retrieval of stratospheric aerosol density profiles from SCIAMACHY limb radiance measurements in the $\mathrm{O}_{2}$ A-band, Atmos. Meas. Tech., 4, 2359-2373, doi:10.5194/amt-4-2359-2011, 2011.

Platt, U. and Stutz, J.: Differential Optical Absorption Spectroscopy: Principles and applications, Springer, Berlin, Heidelberg, 2008.

Penning de Vries, M. J. M., Beirle, S., and Wagner, T.: UV Aerosol Indices from SCIAMACHY: introducing the SCattering Index (SCI), Atmos. Chem. Phys., 9, 9555-9567, doi:10.5194/acp-99555-2009, 2009.

Penning de Vries, M. and Wagner, T.: Modelled and measured effects of clouds on UV Aerosol Indices on a local, regional, and global scale, Atmos. Chem. Phys., 11, 12715-12735, doi:10.5194/acp-11-12715-2011, 2011.

Richter, A. and Wagner, T.: The use of UV, visible, and near IR solar back scattered radiation to determine trace gases, in: The remote sensing of tropospheric composition from space, edited by: Burrows, J. P., Platt, U., and Borell, P., 67-121, Springer, Berlin, Heidelberg, 2011.

Robock, A.: Volcanic eruptions and climate, Rev. Geophys., 38, 191-219, 2000.

Rose, W. I., Gu, Y., Watson, I. M., Yu, T., Bluth, G. J. S., Prata, A. J., Krueger, A. J., Krotkov, N., Carn, S., Fromm, M. D., Hunton, D. E., Ernst, G. G. J., Viggiano, A. A., Miller, T. M., Ballenthin, J. O., Reeves, J. M., Wilson, J. C., Anderson, B. E., and Flittner, D. E.: The February-March 2000 eruption of Hekla, Ice- land from a satellite perspective, Geophys. Monogr. Series, 139, 107-132, 2003.

Sarkissian, A., Pommereau, J. P., and Goutail, F.: Identification of polar stratospheric clouds from the ground by visible spectrometry, Geophys. Res. Lett., 18, 779-782, 1991.

Sawamura, P., Vernier, J.-P., Barnes, J. E., Berkoff, T. A., Welton, E. J., Alados-Arboledas, L., Navas-Guzmán, F., Pappalardo, G., Mona, L., Madonna, F., Lange, D., Sicard, M., Godin-Beekmann, S., Payen, G., Wang, Z., Hu, S., Tripathi, S. N., CordobaJabonero, C., and Hoff, R. M.: Stratospheric AOD after the 2011 eruption of Nabro volcano measured by lidars over the Northern Hemisphere, Environ. Res. Lett., 7, 034013, doi:10.1088/17489326/7/3/034013, 2012.

Smithsonian Institution: Nabro, Bulletin of the Global Volcanism Network, 36, 9, 2011.

Soden, B. J., Wetherald, R. T., Stenchikov, G. L., and Robock, A.: Global cooling after the eruption of Mount Pinatubo: A test of climate feedback by water vapor, Science, 296, 727-730, 2002.

Solomon, S., Schmeltekopf, A. L., and Sanders, R. W.: On the interpretation of zenith sky absorption measurements, J. Geophys. Res., 92, 8311-8319, doi:10.1029/JD092iD07p08311, 1987.

Solomon, S., Daniel, J. S., Neely III, R. R., Vernier, J.-P., Dutton, E. G., and Thomason, L. W.: The persistently variable "background" stratospheric aerosol layer and global climate change, Science, 333, 866-870, 2011.

SPARC: Assessment of stratospheric aerosol properties (ASAP), SPARC Rep., 4, World Clim. Res. Programme, Toronto, Ont., Canada, 2006.

Taha, G., Rault, D. F., Loughman, R. P., Bourassa, A. E., and von Savigny, C.: SCIAMACHY stratospheric aerosol extinction profile retrieval using the OMPS/LP algorithm, Atmos. Meas. Tech., 4, 547-556, doi:10.5194/amt-4-547-2011, 2011.

Theys, N., Campion, R., Clarisse, L., Brenot, H., van Gent, J., Dils, B., Corradini, S., Merucci, L., Coheur, P.-F., Van Roozendael, M., Hurtmans, D., Clerbaux, C., Tait, S., and Ferrucci, F.: Volcanic $\mathrm{SO}_{2}$ fluxes derived from satellite data: a survey using OMI, GOME-2, IASI and MODIS, Atmos. Chem. Phys., 13, 59455968, doi:10.5194/acp-13-5945-2013, 2013.

Torres, O., Bhartia, P. K., Herman, J. R., Ahmad, Z., and Gleason, J.: Derivation of aerosol properties from satellite measurements of backscattered ultraviolet radiation: Theoretical basis, J. Geophys. Res., 103, 17099-17110, 1998.

van Hoek, M. and Claas, J.: Possibilities to avoid row anomaly rows, KNMI Technical Document, TN-OMIE-KNMI-963, 2010.

Vernier, J.-P., Thomason, L. W., Fairlie, T. D., Minnis, P., Palikonda, R., and Bedka, K. M.: Comment on "Large volcanic aerosol load in the stratosphere linked to Asian monsoon transport", Science, 339, 647, doi:10.1126/science.1227817, 2013.

von Savigny, C., Ulasi, E. P., Eichmann, K.-U., Bovensmann, H., and Burrows, J. P.: Detection and mapping of polar stratospheric clouds using limb scattering observations, Atmos. Chem. Phys., 5, 3071-3079, doi:10.5194/acp-5-3071-2005, 2005.

Wagner, T., Beirle, S., Deutschmann, T., Eigemeier, E., Frankenberg, C., Grzegorski, M., Liu, C., Marbach, T., Platt, U., and Penning de Vries, M.: Monitoring of atmospheric trace gases, clouds, aerosols, and surface properties from UV/vis/NIR satellite instruments, J. Opt. A-Pure Appl. Op., 10, 104019, doi:10.1088/14644258/10/10/104019, 2008. 
Wang, P., Stammes, P., van der A, R., Pinardi, G., and van Roozendael, M.: FRESCO+: an improved $\mathrm{O}_{2}$ A-band cloud retrieval algorithm for tropospheric trace gas retrievals, Atmos. Chem. Phys., 8, 6565-6576, doi:10.5194/acp-8-6565-2008, 2008.

Welton, E. J., Campbell, J. R., Spinhirne, J. D., and Scott, V. S.: Global monitoring of clouds and aerosols using a network of micro-pulse lidar systems, in: Lidar Remote Sensing for Industry and Environmental Monitoring, edited by: Singh, U. N., Itabe, T., and Sugimoto, N., Proc. SPIE, 4153, 151-158, 2001.

Winker, D. M., Hunt, W. H., and McGill, M. J.: Initial performance assessment of CALIOP, Geophys. Res. Lett., 34, L19803, doi:10.1029/2007GL030135, 2007.
Yan, H., Chen, L., Tao, J., Su, L., Huang, J., Han, D., and Yu, C.: Corrections for $\mathrm{OMI} \mathrm{SO}_{2} \mathrm{BRD}$ retrievals influenced by row anomalies, Atmos. Meas. Tech., 5, 2635-2646, doi:10.5194/amt5-2635-2012, 2012.

Yang, K., Krotkov, N. A., Krueger, A. J., Carn, S. A., Bhartia, P. K., and Levelt, P. F.: Retrieval of large volcanic $\mathrm{SO}_{2}$ columns from the Aura Ozone Monitoring Instrument: Comparison and limitations, J. Geophys. Res., 112, D24S43, doi:10.1029/2007JD008825, 2007. 